\title{
Changing INPUTS OF CONTINENTAL AND SUBMARINE WEATHERING SOURCES OF SR TO THE OCEANS DURING OAE 2
}

LUCIEN NANA YOBO ${ }^{1 *}$, ALAN D. BRANDON ${ }^{1}$, KIMBERLY $^{2}$ V. LAU ${ }^{2}$, CHRIS HOLMDEN ${ }^{3}$ AND JAMES ELDRETT ${ }^{4}$

${ }^{1}$ Dept. of Earth and Atmospheric Sciences, University of Houston, TX, 77204, (1nanayobo@uh.edu)

${ }^{2}$ Department of Geology and Geophysics, University of Wyoming, Laramie WY

${ }^{3}$ Department of Earth Science, University of Saskatchewan, Saskatoon Canada

${ }^{4}$ Shell International Exploration and Production, the Netherlands

Ocean anoxic events are characterized by increased organic richness of marine sediment on a global scale with accompanying positive excursions in sedimentary organic and inorganic carbon isotope values. Increased supplies of nutrients to the oceans are required to sustain elevated levels of marine productivity necessary to account for high carbon export fluxes during ocean anoxic events. Submarine eruptions of one or more large igneous provinces are the proposed trigger for OAE 2, and the $\mathrm{CO}_{2}$ induced global warming and increased rainfall acidification are both factors that can increased continental weathering rates and therefore nutrient inputs to the oceans. On the other hand, seawater interactions with hot basalts at LIP eruptions sites can deliver ferrous iron and other metals and reduced gases to seawater that can stimulate increased productivity in surface waters and increased oxygen demand in deep waters. The relative importance of continental and submarine weathering drivers of expanding ocean anoxia during OAE 2 are difficult to disentangle. In this talk, we present a new high-resolution record of seawater ${ }^{87} \mathrm{Sr} /{ }^{86} \mathrm{Sr}$ in a pelagic carbonate succession from the Eagle Ford Formation in Texas. With the help of a box model of the ocean $\mathrm{Sr}$ cycle, and knowledge of the contrasting ${ }^{87} \mathrm{Sr} /{ }^{86} \mathrm{Sr}$ signatures of continental weathering and submarine weathering inputs of $\mathrm{Sr}$ to the oceans, we determine the relative magnitudes of the continental weathering and submarine weathering fluxes of $\mathrm{Sr}$ to the oceans during OAE 2. Finally, the new ${ }^{87} \mathrm{Sr} /{ }^{86} \mathrm{Sr}$ data offers a significant refinement to the temporal pattern of changing ${ }^{87} \mathrm{Sr} /{ }^{86} \mathrm{Sr}$ in the global ocean over OAE2. 